\title{
pH-dependent cytotoxic effects of extracts of the marine sponge Polymastia janeirensis on cancer cell lines
}

\author{
Renata Biegelmeyer ${ }^{\mathrm{a}, *}$, Rafael Schröder ${ }^{\mathrm{b}}$, Douglas F. Rambo ${ }^{\mathrm{a}}$, Roger R. \\ Dresch $^{\mathrm{a}}$, João L.F. Carraro ${ }^{\mathrm{c}}$, Beatriz Mothes B ${ }^{\mathrm{d}}$, José Cláudio F. Moreira ${ }^{\mathrm{b}}$, \\ Mario L.C. da Frota Junior ${ }^{\mathrm{b}}$ and Amélia T. Henriques ${ }^{\mathrm{a}}$ \\ ${ }^{a}$ Pharmacognosy Laboratory, Faculty of Pharmacy, Federal University of Rio Grande \\ do Sul (UFRGS), Porto Alegre, RS, Brazil; ${ }^{b}$ Study Center of Oxidative Stress, \\ Biochemistry Department, Federal University of Rio Grande do Sul (UFRGS), Porto \\ Alegre, RS, Brazil; ' National Museum, Department of Invertebrates, Federal University \\ of Rio de Janeiro (UFRJ), Rio de Janeiro, Brazil; ${ }^{d}$ Zoobotanical Foundation, Museum \\ of Natural Sciences, Porto Alegre, RS, Brazil.
}

*Corresponding author: renata.biegel@gmail.com

\begin{abstract}
The purpose of this work was to study the cytotoxic effects of marine sponge Polymastia janeirensis, which has been observed in the field to release an orange substance that is toxic to fish. The result showed that aqueous extract $(\mathrm{pH} 7.0)$ was highly cytotoxic to glioma (U87) and neuroblastoma (SHSY5Y) cancer cell lines $\left(\mathrm{IC}_{50}<1.0 \mu \mathrm{g} / \mathrm{ml}\right.$ ). In addition, this extract showed potent antioxidant and procoagulant (decreased the clotting time by 1.7 fold) activities. Interestingly, the cytotoxic effects were $\mathrm{pH}$-dependent since the viability of the cancer cells was not affected with the extract ( $\mathrm{pH} 5.5)$. The close similarity between the aqueous extract ( $\mathrm{pH}$ 7.0) and the orange liquid that is released by the sponge indicates that this potential chemical defense of $P$. janeirensis deserves further investigation.
\end{abstract}

Keywords: P. janeirensis; chemical defense; cytotoxic; $\mathrm{pH}$-dependent activity. 


\section{Experimental}

\section{Reagents}

3-(4,5-dimethyl)-2,5-diphenyl tetrazolium bromide (MTT), HEPES and Trolox were obtained from Sigma-Aldrich (St. Louis, Mo., USA). Methanol, ethyl acetate and hexane (high-performance liquid chromatography [HPLC] grade) were purchased from Tedia (Fairfield, Ohio, USA).

\section{Sponge collection}

Samples of the marine sponge Polymastia janeirensis were collected by hand at depths of between 10-15 m from locations along the coastline of Santa Catarina, Brazil. The specimen was deposited by the number MCN 8922 at the Museum of Natural Sciences, Porifera collection of the Fundação Zoobotânica do Rio Grande do Sul, Brazil.

\section{Preparation of extracts and fractions}

The marine sponge samples were initially freeze-dried. The extracts were prepared using animal samples by the Ultra-Turrax system with methanol. Considering that $P$. janeirensis releases an orange substance when severed, extracts were also prepared with distilled water aliquots that were maintained at distinct $\mathrm{pH}$ levels (5.5, 6.0, 6.5, 7.0, 7.5 and 8.0). The $\mathrm{pH}$ was adjusted with solution of $\mathrm{NaOH} 1.0 \mathrm{M}$ or $\mathrm{HCl} 1.0 \mathrm{M}$.

To obtain a polarity based fractionation, the raw methanol extracts were partitioned with other solvents to obtain the initial aqueous, hexane and ethyl acetate (EtOAc) fractions. First, the methanol extracts were concentrated and adjusted to 9:1 $\left(\mathrm{MeOH}: \mathrm{H}_{2} \mathrm{O}\right.$ ). The $\mathrm{MeOH}: \mathrm{H}_{2} \mathrm{O}$ suspensions were partitioned against hexane. Next, the methanol was evaporated from each sample using a rotary evaporator, and the remaining aqueous suspension was partitioned against EtOAc.

\section{Evaluation of cytotoxic effects}

\section{Cell cultures}

The human glioma (U87) and human neuroblastoma (SHSY5Y) cell lines were obtained from the American Type Culture Collection (Rockville, MD, USA). The glioma cells were grown and maintained in low-glucose Dulbecco's modified Eagle's medium (DMEM; Gibco BRL, Carlsbad, USA), which contained 0.1\% fungizone and $100 \mathrm{U} / 1$ gentamicin and was supplemented with $10 \%$ fetal bovine serum (FBS). The neuroblastoma cells were grown and maintained in a 1:1 mixture of Ham's F12 and 
DMEM that was supplemented with $10 \%$ heat-inactivated FBS, $2 \mathrm{mM}$ of glutamine, $0.28 \mu \mathrm{g} / \mu \mathrm{l}$ of gentamicin and $250 \mu \mathrm{g}$ of amphotericin B. Cells were plated in 96-well plates $\left(10^{4} /\right.$ well) and were incubated at $37^{\circ} \mathrm{C}$ in a humidified atmosphere with $5 \% \mathrm{CO}_{2}$. The media were replaced every 3 days, and all treatments were performed when the cells reached confluencies of $70-80 \%$.

\section{Treatments}

The aqueous extracts and fractions were dissolved in water and dimethylsulfoxide (DMSO) to final concentrations of 10 and $50 \mathrm{mg} / \mathrm{ml}$ (dried extract weight, $w / v$ ), respectively. Successive dilutions were made with DMEM medium to final concentrations ranging from 0.1 to $100 \mu \mathrm{g} / \mathrm{ml}$ in multi-well plates. The cultures were incubated with the sponge extracts and fractions for $24 \mathrm{~h}$. The final concentration of DMSO $(0.25 \%)$ was proven not to affect the experiments. The control cultures were treated identically of samples (with the same solvent), except that the extracts were not used.

\section{Assessments of glioma and neuroblastoma cell viabilities}

Cell viabilities were determined by the MTT assay. Following the treatments, the medium was discarded, and fresh medium containing $0.5 \mathrm{mg} / \mathrm{ml}$ MTT was added. The cells were incubated for $45 \mathrm{~min}$ at $37^{\circ} \mathrm{C}$ in a humidified atmosphere with $5 \% \mathrm{CO}_{2}$. After, this medium was removed, and DMSO was added for $30 \mathrm{~min}$ to solubilize the formazan crystals. Absorbances were measured at $550 \mathrm{~nm}$ (test) and $690 \mathrm{~nm}$ (reference) using a SoftMax Pro Microplate Reader (Molecular Devices®, USA). The half maximal inhibitory concentration values $\left(\mathrm{IC}_{50}\right)$ were estimated from a semilog plot of the fractions and extract concentrations versus the percentages of tumor cell line growth inhibition.

\section{Total reactive antioxidant potential (TRAP) method}

The TRAP method, as described by Dresch et al. (2009), was used to estimate the in vitro antioxidant capacity with a liquid scintillator counter (Wallac 1409, Perkin Elmer, Boston, MA, USA). The samples were diluted with glycine buffer to final concentrations of $1.0-100 \mu \mathrm{g} / \mathrm{ml}$ (dried extract weight, $w / v$ ). The final percentage of DMSO $(0.25 \%)$ was proven not to affect the system. The results were expressed as a plot of the percentage of counts per minute $(\% \mathrm{cpm})$ versus the time $(\mathrm{s})$ and area under 
the curve (AUC). The Trolox equivalent antioxidant capacity (TEAC) was estimated using the standard curve of Trolox (between 0.05 and $0.4 \mu \mathrm{M}$ ) and the AUC.

\section{Clotting assay}

Recalcification times (RTs) were assessed using a SpectraMax microplate ELISA reader as described by Ribeiro et al. (1995), with some modifications. Briefly, $50 \mu$ of human citrated platelet-poor plasma was incubated for 5 min with $80 \mu \mathrm{l}$ of $20 \mathrm{mM} \mathrm{HEPES,} \mathrm{pH}$ 7.4 , with or without (control) varying amounts of extracts and fractions: $1.0-100 \mu \mathrm{g} / \mathrm{ml}$ (dried extract weight, $w / v$ ). Coagulation was triggered by adding $\mathrm{CaCl}_{2}$ to a final concentration of $10 \mathrm{mM}$, and clot formation was monitored at $37^{\circ} \mathrm{C}$ using the SpectraMax system at a wavelength of $650 \mathrm{~nm}$ at $15 \mathrm{~s}$ intervals for $20 \mathrm{~min}$. Samples were diluted with HEPES buffer to their final concentrations, and the final percentage of DMSO $(0.25 \%)$ was proven not to affect blood coagulation. Clotting was indicated by a rapid and sharp increase in absorbance following a lag phase. A variation of 0.05 in the absorbance value (onset time) was defined as the measurement of the recalcification time, using the module that was included in the instrument software.

\section{Statistical analysis}

The in vitro procedures were carried out with $\mathrm{n}=3$, while cell culture experiments were conducted with $\mathrm{n}=3$ in at least three independent experiments. Data were expressed as mean \pm standard error of the mean (SEM). The results were evaluated by one-way analysis of variance (ANOVA) followed by Tukey's post hoc test. The differences were considered statistically significant if $P<0.05$. Data analyses were performed using the GraphPad software ${ }^{\circledR}$, San Diego, CA; version 5.00. 
Table S1. Cytotoxic effects in human neuroblastoma and glioma cell lines of $P$. janeirensis aqueous extracts in different $\mathrm{pH}$ levels.

\begin{tabular}{|c|c|c|}
\hline \multirow{2}{*}{$\begin{array}{c}\text { P. janeirensis } \\
\text { Aqueous Extract }\end{array}$} & \multicolumn{2}{|c|}{$\mathrm{IC}_{50}(\mu \mathrm{g} / \mathrm{ml})^{\mathrm{a}}$} \\
\hline & $\begin{array}{l}\text { glioma } \\
\text { (U87) }\end{array}$ & $\begin{array}{c}\text { neuroblastoma } \\
\text { (SH-SY5Y) }\end{array}$ \\
\hline pH 5.5 & na & na \\
\hline pH 6.0 & $1.89 \pm 1.38$ & $1,76 \pm 1.40$ \\
\hline pH 6.5 & $0.75 \pm 0.35$ & $0.35 \pm 0.32$ \\
\hline pH 7.0 & $0.78 \pm 0.28$ & $0.22 \pm 0.20$ \\
\hline pH 7.5 & $0.74 \pm 0.10$ & $0.25 \pm 0.24$ \\
\hline pH 8.0 & $0.80 \pm 0.20$ & $0.28 \pm 0.33$ \\
\hline
\end{tabular}

${ }^{\mathrm{a}}$ All values given are the mean \pm SEM of dried extract/fraction weight; na: not active. 


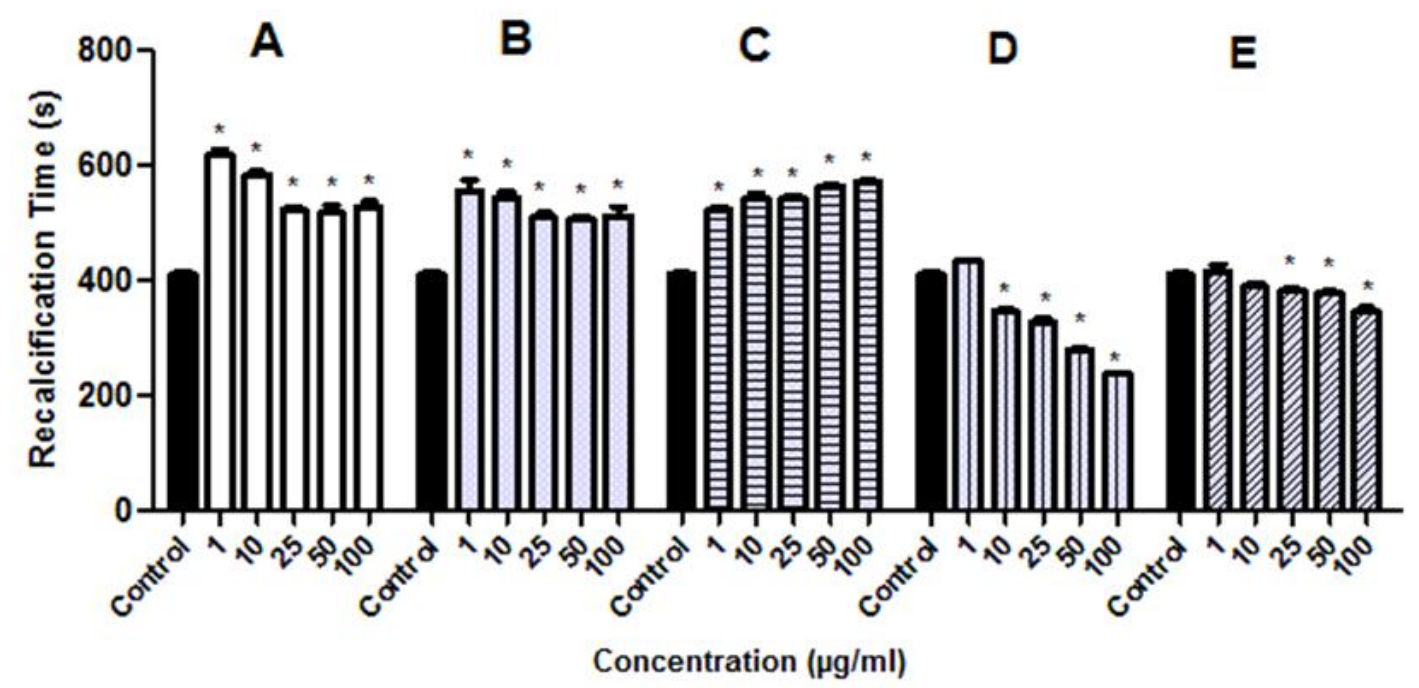

Figure S1. Effect of extracts of the marine sponge $P$. janeirensis on blood coagulation, as represented by recalcification time: anticoagulant activity of the EtOAc fraction (A), hexane fraction (B) and aqueous fraction (C) and the procoagulant activity of aqueous extract at pH 7.0 (D) and aqueous extract at pH 5.5 (E). Bars represent means \pm SEM. Asterisks denote significance at $p<0.05$ compared with control (one-way ANOVA followed by Tukey’s test). 


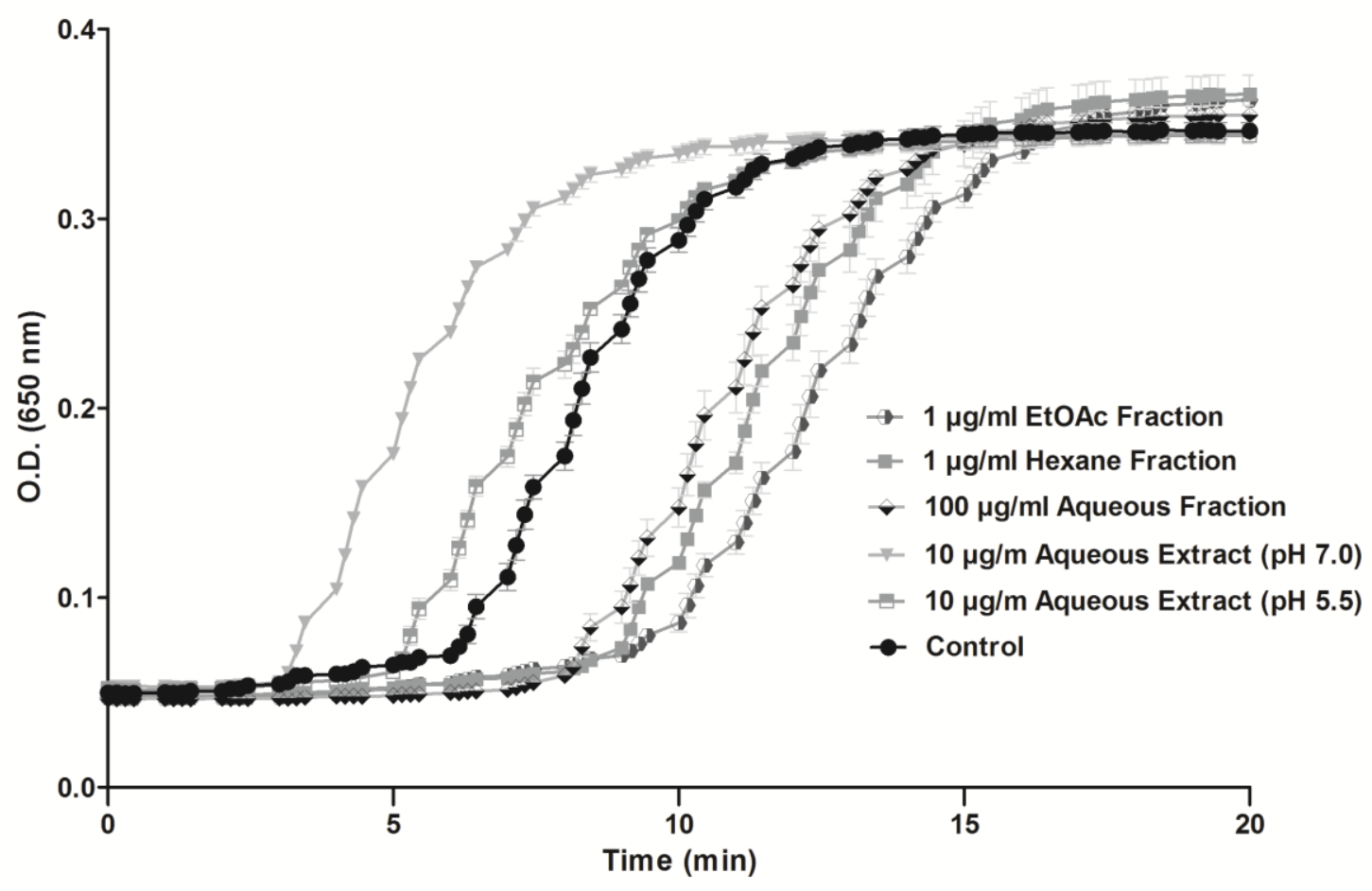

Figure S2. Profile of changes in blood coagulation of $P$. janeirensis fractions and extracts. The concentrations that exhibited the highest anticoagulant or procoagulant activities are shown. Bars represent means \pm SEM. 


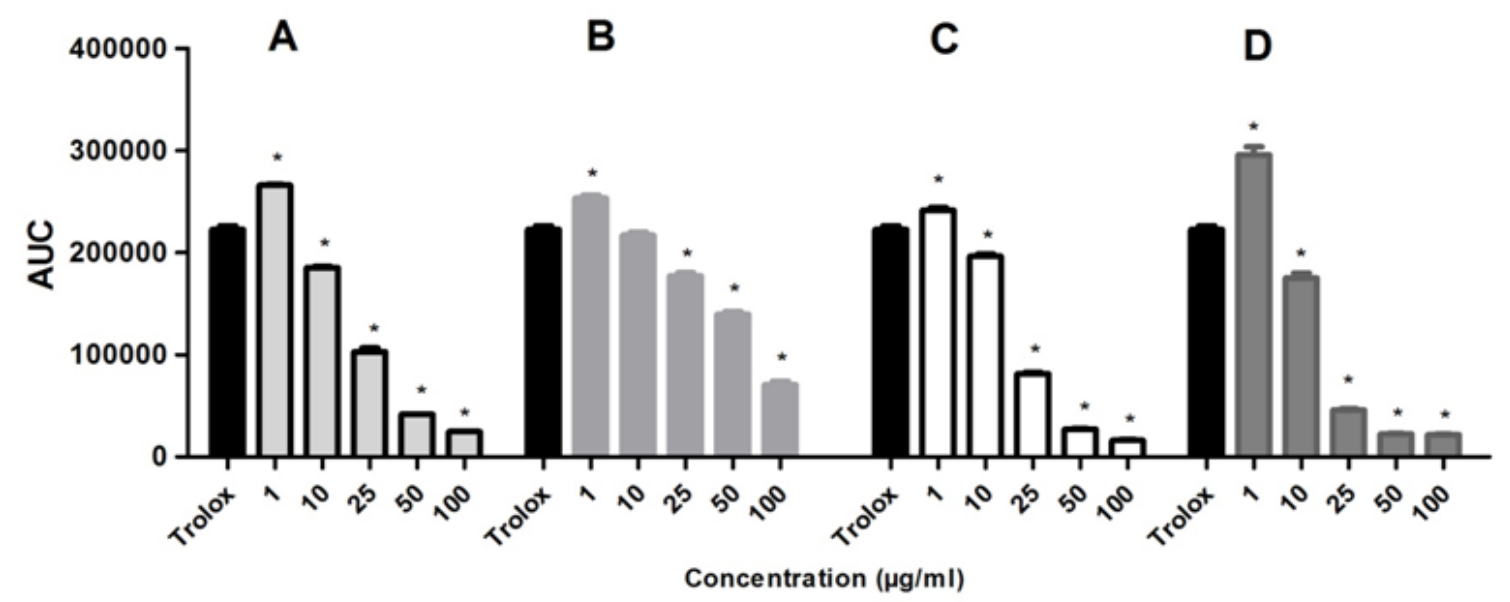

Figure S3. TRAP of $P$. janeirensis: EtOAc fraction (A), aqueous fraction (B), aqueous extract at $\mathrm{pH} 7.0$ (C) and aqueous extract at $\mathrm{pH} 5.5$ (D). Effects of different concentrations of fractions and extracts on free radical-induced CL were measured as AUC values. Trolox $(0.05 \mu \mathrm{g} / \mathrm{ml})$ was used as standard antioxidant. Bars represent means \pm SEM. Asterisks denote significance at $p<0.05$ compared with control (oneway ANOVA followed by Tukey’s test). 

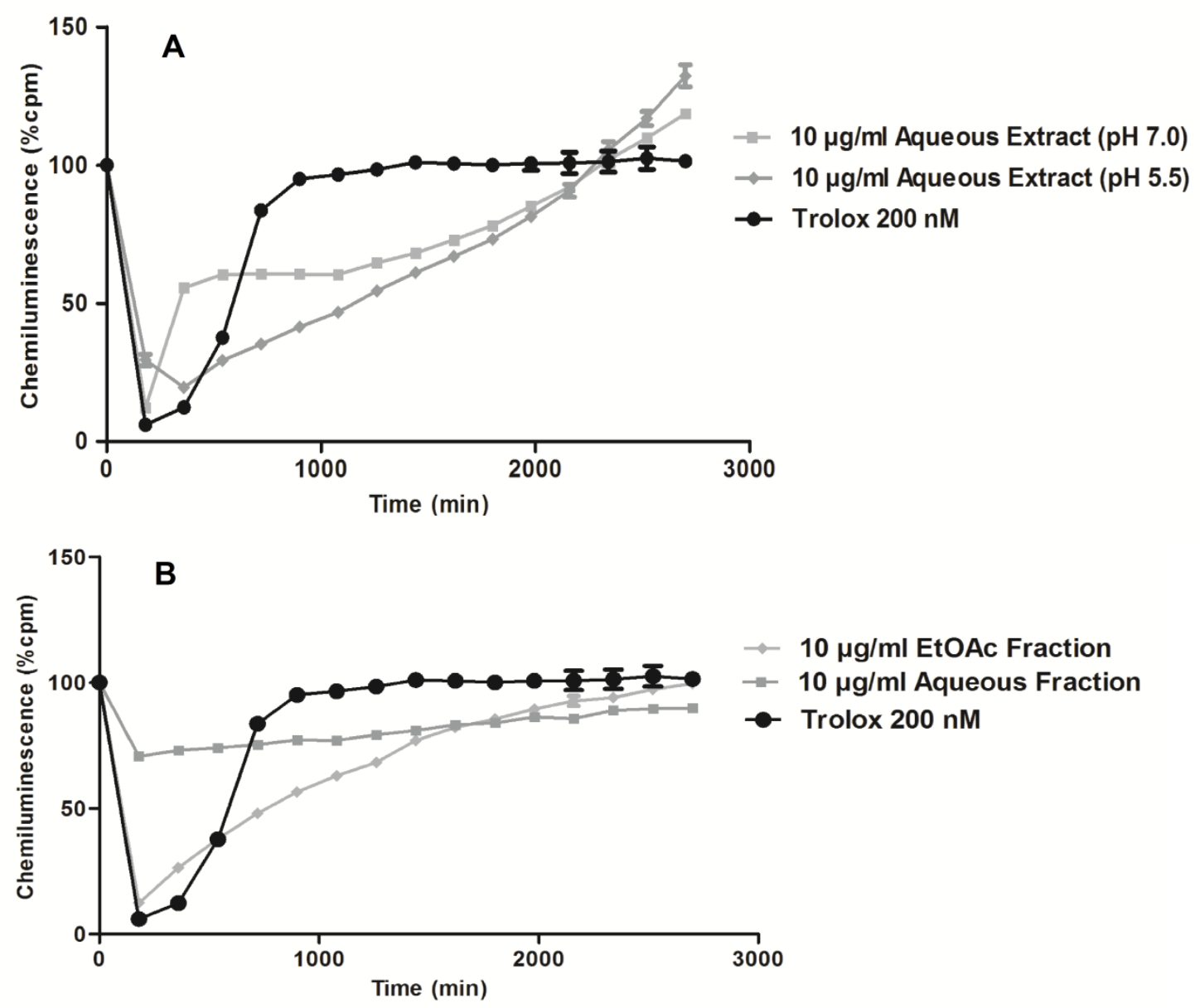

Figure S4. CL intensity $(\% \mathrm{cpm})$ measured after addition of extracts (A) and fractions (B) of P. janeirensis. CL profiles are shown for samples at concentrations that exhibited similar AUC values to those of the Trolox standard. 


\section{References}

Dresch MTK, Kappel VD, Rossato SB, Biegelmeyer R, Mayorga P, Zuanazzi JAS, Henriques AT, Moreira JCF. 2009. Optimization and validation of an alternative method to evaluate Total Reactive Antioxidant Potential (TRAP). Anal Biochem. 385:107-114.

Ribeiro JM, Schneider M, Guimarães JA. 1995. Purification and characterization of prolixin S (nitrophorin 2), the salivary anticoagulant of the blood-sucking bug Rhodnius .prolixus. Biochem J. 308:243-249. 